\title{
SAMPLING PLAN FOR THE ANALYSIS OF AFLATOXIN IN PEANUTS AND CORN: AN UPDATE
}

\author{
Homero Fonseca* \\ Departamento de Produção Vegetal, Escola Superior de Agricultura “Luiz de Queiroz”, Universidade de São Paulo, \\ São Paulo, SP, Brazil.
}

Submitted: June 14, 2002; Approved: July 31, 2002

\section{MINI - REVIEW}

\begin{abstract}
The aim of this paper was to update the sampling plan for analysis of mycotoxins in grains, formerly published by the author. The proposed alterations were based on the acquired experience on its application and on FAO recommendations. This update restricts the scope of the former plan and establishes a sampling plan for analysis of aflatoxin in peanuts and corn, by means of modified formulas, the minimum number of sacks or points (when in bulk) from which incremental samples should be drawn to make a bulk sample. Fractional exponents (square roots) of the formulas proportionally decrease the number of sacks/points to be sampled as the lot size increases. Operating Characteristic (OC) curves developed for in-shell and shelled peanuts and corn as well as trend curves of the coefficient variation for different sample sizes (weights) are presented.
\end{abstract}

Key words: Sampling, peanuts, corn, aflatoxin, analysis.

\section{INTRODUCTION}

Sampling is, no doubt, the most important factor of the variation found when testing lots of grains for aflatoxin. The main difficulty in sampling grains for mycotoxins analysis is normally due to the small percentage of contaminated kernels in a lot (8) and to the considerable variation in the amount of toxin in the contaminated kernels. This variation has been demonstrated in peanuts (1), in cottonseed (5) and in corn (9) especially in non-processed grains.

The problem of sampling shelled peanuts for aflatoxin analysis has been intensely investigated and discussed by Whitaker et al. (10,11,12,13,14 e 15). Whitaker et al. (10) reported that the distribution of aflatoxin in a lot of shelled peanuts could be quantitatively represented by the negative binomial function.

Mathematically simulating the sampling procedure they demonstrated that the results of aflatoxin analysis in a sample is affected (a) by the size of the sample, (b) by the mean aflatoxin concentration in the lot and (c) by the percentage of contaminated kernels in the lot. These relations were expressed as tables of probability (14).
Jewers (4), of the former Tropical Products Institute - TPI (today, Natural Resources Institute-NRI), of England, based on the North American sampling plan, developed an alternative plan for a lot of 20 tons ( 400 sacks of $50 \mathrm{~kg}$ ) of shelled peanut which sought to reduce the amount and the weight of samples of the lot to reduce the risk of the producer to have a good lot rejected, without increasing the consumer's risk significantly. His plan foresaw to draw at least 100 increments of $105 \mathrm{~g}$ of the lot, achieving a bulk sample of $10.5 \mathrm{~kg}$ that was divided in 3 subsamples of equal weights analyzed individually. The North American plan foresees to draw 3 samples of $22.0 \mathrm{~kg}$ each. The application of the TPI plan, in practice, demonstrated that, compared to the North American plan, produced a slight increase in the consumer's risk (CR) and a small decrease in the producer's risk. Table 1 shows the comparison between the consumer's risks $(\mathbf{C R})$ and the producer's risks (PR) of the plan TPI against the USA plan. The TPI plan devised a fixed number of increments and samples to be drawn from a lot, independently of the lot size. It just recommended that, when a lot went larger than 50 ton, the lot should be separated into smaller sub-lots for sampling.

\footnotetext{
* Corresponding author. Mailing address: Rua Dona Eugênia, 269. 13416-218, Piracicaba, SP, Brasil. Phone: (+5519) 3422-7137, Fax: (+5519) 3434-
} 5190. E-mail: hfonseca@merconet.com.br 
Table 1. A comparison of TPI and USA sampling plans.

\begin{tabular}{lcccc}
\hline & \multicolumn{3}{c}{ Maximum Permitted Level } \\
\cline { 2 - 5 } & $\begin{array}{c}25 \mu \mathrm{g} / \mathrm{kg} \text { of } \\
\text { aflatoxin }\end{array}$ & \multicolumn{2}{c}{$\begin{array}{c}30 \mu \mathrm{g} / \mathrm{kg} \text { of } \\
\text { aflatoxin }\end{array}$} \\
\cline { 2 - 5 } & $\mathrm{CR}$ & $\mathrm{PR}$ & $\mathrm{CR}$ & $\mathrm{PR}$ \\
\hline TPI Plan $(3 \times 3.5 \mathrm{~kg})$ & $1.4 \%$ & $0.7 \%$ & $0.6 \%$ & $0.8 \%$ \\
USA Plan $(3 \times 22 \mathrm{~kg})$ & $0.6 \%$ & $0.9 \%$ & $0.2 \%$ & $1.3 \%$ \\
\hline
\end{tabular}

Practical problems can emerge when the lots or consignments are too large such as in ships, railroad wagons, big stacks, and when samples are drawn superficially: they may not be representative.

The recommended sampling plan of the Ministry of Agriculture of Brazil, issued in 1981, and still officially in use, establishes a linear sampling of $10 \%$ of the sacks, taking "a minimum of $30 \mathrm{~g}$ from each sack". When peanuts are in bulk it says that if the lot is larger than 500 ton, " $40 \mathrm{~kg}$ of material must be taken, randomly; if larger than 500 ton, $40 \mathrm{~kg}$ must be taken from each 500 ton or fraction". The samples must be thoroughly blended and divided in three parts, of which only one is analyzed keeping the other two for further analysis as counterproofs. This plan may be suitable for classification purposes but not for aflatoxin or other mycotoxins analyzes for the reasons pointed above.

The Brazilian market is quite peculiar for brokers and/or food manufacturers work with very diverse sizes of lots and, therefore, drawing a fixed number or weight of samples does not meet their needs and is not convenient because very often they work with small lots down to 20,30 or 50 sacks ( 1 to 2.5 ton) of peanuts many times utilized by the so-called "backyard industry".

In 1985 the Ministry of Agriculture of Brazil decided to improve the sampling procedures for aflatoxins and the author of this paper has published, in 1991, an empirical sampling plan (3), based on the TPI method and taking in consideration the difficulties and peculiarities of Brazil, that could determine the mean aflatoxin content and, maybe, other mycotoxins of a lot, with a reasonable grade of confidence and that could attain to acceptable levels the producers' and the consumers' risks. (PR and $\mathbf{C R}$ ). This plan should also be acceptable when losses, cost of the amount of material taken and cost of the analytical procedures as well are concerned.

Ideally the PR and $\mathbf{C R}$ should be equal to zero but this is practically impossible because of the variability associated with the aflatoxin test procedure. Both $\mathbf{C R}$ and $\mathbf{P R}$ can be reduced at the same time if more intense sampling is carried out, but this would rise the cost and time needed to take a decision on accepting or rejecting the lot.

After ten years experiencing the behavior of this methodology (3) the author decided to revise it and to introduce some recommendations issued by the FAO meeting of 1993, when experts and advisers from twenty countries were gathered by the Food and Agriculture Organization (FAO) of the United Nations in the "Technical Consultation on Sampling Plans for Aflatoxin Analysis in Peanuts and Corn" to propose a sampling methodology that could be applied by different organs and industries around the world and that could produce consistent results. The document issued from that meeting became the "Sampling Plans for Aflatoxin Analysis in Peanuts and Corn" (2).

The major modifications were introduced in the formulas to calculate the number of increments to draw from a lot of in-shell peanuts, shelled peanuts and corn, either in sacks or in bulk, in order to increase the number of sacks or points from which to draw increments and, therefore, increase the size of the sample.

The size of the sample was also increased to $5.0 \mathrm{~kg}$, instead of $4.0 \mathrm{~kg}$ of the former method. It is suggested to collect a higher amount of sample from lots, to diminish the coefficient of variation of the results.

Additional recommendations were also made in sample care, such as packing, transportation and tagging to preserve the samples conditions after their collection.

Operating Characteristic (OC) curves were calculated for inshell and shelled peanuts and for corn, as well as, trend curves for the coefficient of variation in function of the sample size (weight).

\section{THE METHOD}

The method utilizes formulas developed based on the amount of sample devised by the former TPI Plan 1 (4) and on the practical experience of the author, with square roots to calculate the number of sacks from which incremental samples must be taken from lots of any size and suggests criteria for accepting and rejecting lots. Taking in consideration the amount of sample drawn from a lot of by the TPI plan (not strictly but approximately) from a 20 tons lot, the author has developed formulas, to draw not a fixed number of increments or samples but proportionally decreasing the number of samples as the lot went smaller and vice-versa.

So, the sampling plan, is not linear for it utilizes square roots whose aim is to proportionally lower the number of sacks from which incremental samples must be taken as the lot increases in size. The amount of incremental samples to be taken from each accessed point in the sacks does not vary but the number of sacks from which to take incremental samples will increase to afford the appropriate bulk sample weight.

This methodology, eventually, may be applied to grains of similar sizes other than peanuts and corn, such as, beans, soybean, etc. once scientists, brokers and food processors, are utilizing it today as minimum sampling, here and abroad, for research work and routine quality control.

\section{Collecting samples}

a) It is always preferable and convenient to collect samples when the lots are in movement. The actual aflatoxin content of a lot is more likely to be determined when representative samples are taken during building or dismantling the stacks, loading or 
unloading trucks, wagons, ships and so on. When an automatic and mobile sample collection is not possible, a person can be assigned to manually pass a cup through the stream at periodic intervals to collect incremental samples that should be increased (2).

b) Ideally, specially when large lots are considered, an automatic sampling system should be utilized.

c) For unprocessed materials, each sample should be composed of, at least, 100 incremental samples taken in a systematic random manner, from the highest number of points of the lot, to be representative.

To avoid misunderstandings with the term subsample, that in Brazil is usually utilized to designate the incremental samples as well as to the subsample as such, it is proposed the following nomenclature (some of these terms have already been adopted in Brazil):

- Increment (incremento) or incremental sample (amostra incremental): applied to the small portions that are taken to compose a bulk sample (amostra). It is equivalent to the term "simple sample" (amostra simples) of the Ministry of Agriculture of Brazil.

- Bulk Sample (Amostra): to the resulting reunion of all incremental samples taken from the lot. It corresponds to the term: compound sample (amostra composta ou global) of the Ministry of Agriculture.

- Working sample (amostra de trabalho): to the portion resulting from the division of the bulk sample and that will be worked on.

- Analytical portion (porção analítica) or analytical sample (amostra analitica): to the portion that effectively will be analyzed.

The proposed formulas to calculate the number of sacks to be sampled are different for different kinds and conditions of the grains, as follows.

The numbers that multiply the square roots were adjusted to obtain a higher amount (weight) of sample than the previous plan. The minimum sample weight adopted for in-shell peanuts is of 7.0 $\mathrm{kg}$ and for shelled peanuts and corn is of $5.0 \mathrm{~kg}$. These figures may not be ideal to achieve low coefficients of variation (see Figs. 1 and 2) but, by the moment, is the realistic sample size that can be exercised by brokers, middlemen and food processors in this country but they are encouraged to work with at least, $10.0 \mathrm{~kg}$ and even more. It is hoped that in the near future these sample weights will rise, although some processors are utilizing, today, $10.0 \mathrm{~kg}$.

\section{Peanuts in sacks}

\subsection{In-shell peanuts:}

$N S=6 \sqrt{S L}$

Where:

$\boldsymbol{N S}=$ minimum number of sacks to be sampled

$\boldsymbol{S L}=$ number of sacks of the lot
In the case of in-shell peanuts, c. $0.2 \mathrm{~kg}$ must be taken from each sack to be sampled. Combine all these incremental samples till they produce a bulk sample of about $7.0 \mathrm{~kg}$, which should be analyzed individually for aflatoxin. This will stick the individual bulk sample to the part or location of the lot or batch from which it was taken.

The minimum amount of in-shell peanuts to be taken from a lot, to compose an in-shell bulk sample, is $7.0 \mathrm{~kg}$. This is the minimum size of the bulk sample and not the minimum size of the incremental sample. If the number of sacks to be sampled, as indicated by the formula, is not enough, more sacks must be sampled to produce the minimum of $7.0 \mathrm{~kg}$.

\subsection{Shelled peanuts:}

$$
N S=4 \sqrt{S L}
$$

When NS is equal to or higher than SL, all sacks must be sampled and some of them, sampled twice.

In the case of shelled peanuts, c. $0.2 \mathrm{~kg}$ must be taken from each sack to be sampled. In the same way, join these incremental samples till they produce a bulk sample of $5.0 \mathrm{~kg}$, (corresponding, approximately, to 25 sacks) which should be analyzed individually for aflatoxin.

The minimum amount of shelled peanuts to be taken from a lot, to compose a bulk sample, is $5.0 \mathrm{~kg}$. This is the minimum size of the bulk sample and not the minimum size of the incremental sample. When the lot has a fewer number of sacks to be sampled than those of indicated by the formula, more sacks must be sampled to produce a minimum of $5.0 \mathrm{~kg}$, some of them, sampled twice.

It would be highly desirable and very much encouraged that at least 10 to $20 \mathrm{~kg}$ of in-shell or shelled peanuts should be drawn. This would lower the coefficient of variation and would give a more precise picture of the actual mean concentration of aflatoxin of the lot being sampled (Figs. 1 and 2).

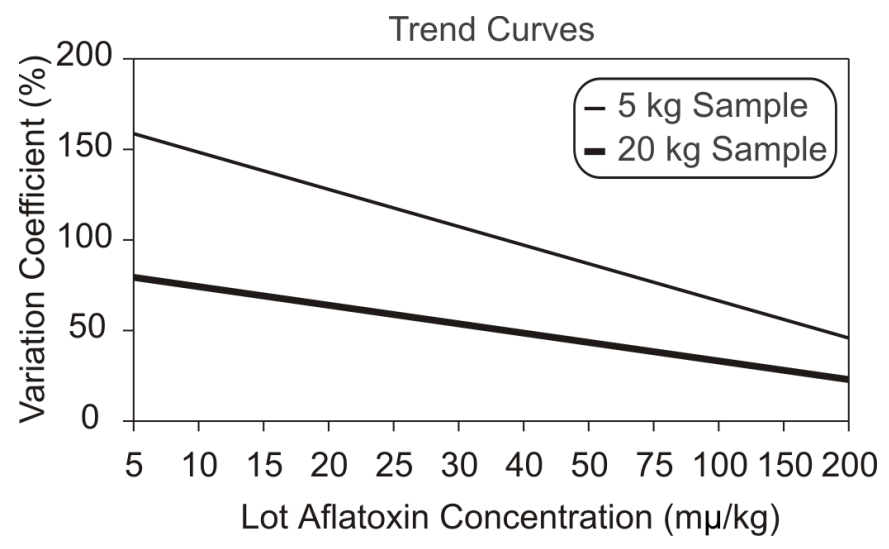

Figure 1. Influence of sample weight on the variation coefficient when sampling shelled peanuts. 


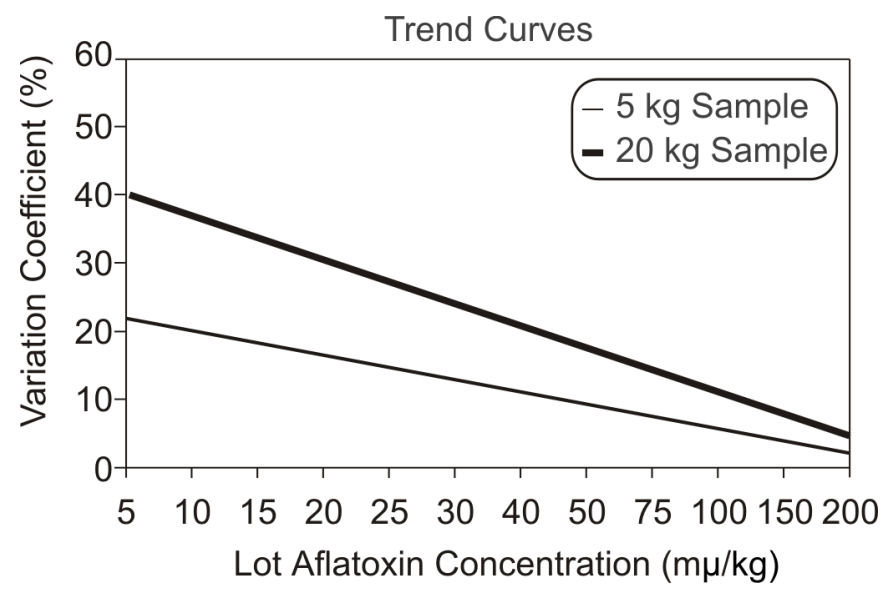

Figure 2. Influence of sample weight on the variation coefficient when sampling shelled corn.

\section{Peanuts in bulk}

\subsection{In-shell peanuts:}

$N P=24 \sqrt{T L}$

$\boldsymbol{N P}=$ minimum number of points to be sampled

$\boldsymbol{T L}=$ number of tons of the lot

\subsection{Shelled peanuts}

$N P=18 \sqrt{T L}$

The same recommendations apply as for peanuts in sacks.

\section{Shelled Corn in sacks}

$N S=4 \sqrt{S L}$

The same recommendations apply as for peanuts in sacks.

\section{Shelled corn in bulk}

$$
N P=4 \sqrt{S L}
$$

The same recommendations apply as for peanuts in sacks.

\section{EXAMPLES}

\section{Peanuts and corn in sacks}

\section{A. Lots of 10 sacks}

\section{In-shell peanuts:}

$N S=6 \sqrt{10}=18.9 \approx 19$ sacks must be sampled i.e., all sacks should be sampled, almost all of them, twice.

Shelled peanuts and corn:

$N S=4 \sqrt{10}=\mathbf{1 2 . 6} \approx \mathbf{1 3}$ sacks must be sampled i.e., all sacks should be sampled, three of them, twice.
B. Lots of 300 sacks:

In-shell peanuts:

$N P=6 \sqrt{300}=103.9 \approx 104$ sacks must be sampled

104 sacks $\times 0.2 \mathrm{~kg} / \mathrm{sack}=20.8 \mathrm{~kg} / 7.0 \mathrm{~kg}=2.97 \approx 3$ samples should be analyzed.

It is advisable that each time the collected incremental samples complete a sample to keep it apart in $7.0 \mathrm{~kg}$ portions (in-shell peanuts) or $5.0 \mathrm{~kg}$ portions (shelled peanuts and corn) analyzing separately the resultant samples. In this case, be sure to identify the site of the lot it comes from. It should be remembered that the 7.0 and $5.0 \mathrm{~kg}$ samples will be representative of that site of the lot from which they have been collected and that only the homogenized bulk or global sample will be "representative" of the complete batch. This procedure, if applied, may lead to a better identification of the contamination levels of the different parts of large lots. However, if it is decided not to analyze samples separately, a careful homogenization and an appropriate subsampling must be applied. Alternatively and for a "representative sample" of the lot, the whole bulk sample should be ground, homogenized and subsampled to obtain the working sample.

NOTE: Every time the number of samples to be analyzed is a fraction, it should be rounded to the next integer, when the fraction is equal or higher than 0.5 .

Shelled peanuts and corn:

$N S=6 \sqrt{300}=69$ sacks must be sampled

69 sacks $\times 0.2 \mathrm{~kg} / \mathrm{sack}=13.8 \mathrm{~kg} / 5.0 \mathrm{~kg}=2.76 \approx 3$ samples should be analyzed

\section{Peanuts and corn in bulk}

\section{Lots of 50 tons}

A. In-shell peanuts

$$
N P=24 \sqrt{50}=169.7 \approx 170 \text { points must be sampled }
$$

170 points $x 0.2 \mathrm{~kg} / \mathrm{sack}=34 \mathrm{~kg} / 7.0 \mathrm{~kg}=4.8 \approx 5$ samples should be analyzed

\section{B. Shelled peanuts and corn}

$$
N P=18 \sqrt{50}=127 \text { points must be sampled }
$$

127 points $x 0.2 \mathrm{~kg} / \mathrm{sack}=25.4 \mathrm{~kg} / 5.0 \mathrm{~kg}=5.1 \approx 5$ samples should be analyzed

Four tables are included, as annexes, to simplify the work of sampling giving ready-made calculations till 2000 sacks (in-shell and shelled peanuts and shelled corn) and 500 tons when in bulk (in-shell peanuts and corn). 


\section{Packing and tagging the sample}

Pack the individual samples in appropriate paper bags or in cardboard boxes that shall not permit peanuts or corn to absorb humidity to minimize the chances of spoilage. DO NOT pack warm or hot grains for they will release water vapor that will condense on the grains or package surfaces and provide water activity that may enable fungi development and mycotoxins production. Details of the samples must be recorded as well as tagged properly, according to the site of the lot where they come from (Table 2).

\section{Sample care}

It is of the utmost importance that the sample be kept as in its original state. If possible it should be kept refrigerated until analyzed. It is absolutely necessary to protect it from heat and from any possibility of absorbing moisture that could allow fungi to develop and produce mycotoxins. If this would happen the analytical results would not reveal the actual contamination of the lots.

\section{Transportation}

During transportation the sample must also be protected against heat and moisture absorbing, for the same reasons stated above.

\section{Sample preparation}

Daylight should be excluded as much as possible during the procedure, since aflatoxin gradually breaks down under ultraviolet light.

In large lots the collection of samples may end with a great amount of material. In this case it is necessary that the final sample (working sample) be produced (by reduction) in the highest random manner by means of utilization of subsamplers such as:

Table 2. Informations that must be provided with the sample.

\begin{tabular}{cc}
\hline $\begin{array}{c}\text { Sample informations } \\
\text { (Informações da amostra) }\end{array}$ & $\begin{array}{c}\text { Tag informations } \\
\text { (Informações da etiqueta) }\end{array}$ \\
\hline Product & No. of seal \\
(Produto) & (No. do lacre) \\
Lo. of the lot or batch & (Tamanho do lote) \\
(No. do lote) & Time of collection \\
Day of collection & (Hora da colheita) \\
(Dia da colheita) & Place \\
City & (Local) \\
(Cidade) & Collector's signature \\
Name of sampler & (Assinatura do amostrador) \\
(Nome do amostrador) & \\
Conditions of the lot & \\
(Condições do lote) & \\
Observations & \\
(Observações) & \\
\hline
\end{tabular}

a) Subsampler mill (like Romer RAS mill or similar): Ideally, the original bulk sample should be ground and then subdivided utilizing a subsampler mill. The utilization of this type of mill is highly recommended, because as they grind the sample into a desired particle size a percentage of the material can be taken systematically for the analysis.

b) Centrifugal divider (like Riffle or Gamet): It employs a centrifugal force to mix and spread the grains over the dividing surface that splits the sample in two equal parts. This can also be used after grinding the bulk sample, if a sub-sampling mill is not available.

c) Conic divider (like Boerner): Samples are fed by gravity from a hopper down the outside of a smooth cone divided at the bottom into 36 streams of grain which are grouped into two outlets. Samples of free flowing grain may be rapidly divided into smaller subsamples.

The utilization of quartering devices should be kept only as a last resource as it is advised by FAO (2).

It is of utmost importance that the final part to be analyzed (analytical sample or analytical portion) represents the original sample.

\section{Grinding and/or comminution of the samples}

In-shell peanuts must be shelled by hand or by any suitable device before comminuting. Grind or comminute samples either with the sampling mill or with a hammer mill. For peanuts should be used a \#14 mesh screen and for corn a \#20 mesh screen. A better homogenization can be obtained through more sophisticated equipment or by water slurry, resulting in a lower sample preparation variance. A water slurry of the whole working sample is recommended, taking then a $100 \mathrm{~g}$ for analysis. When appropriate equipment, for making slurry of the whole working sample is not available, multiple slurries can be the solution. Make partial slurries of equal parts (say, $1.0 \mathrm{~kg}$ each) of the working sample and take equivalent parts (say, 100g) of the resulting slurries combining and homogenizing them and then taking $100 \mathrm{~g}$ for analysis. The slurry must be homogenous and stable not producing supernatants.

For shelled peanuts it is highly recommended (2) to make slurries and the best proportion peanuts:water is $1: 1$. However, the proportion that makes stable slurry may vary a little depending on the peanut variety, water content of the sample and the grade of comminution that the equipment can achieve.

\section{Sample analysis}

Analyze sample utilizing a validated analytical method with a detection limit of, at least, $1 \mu \mathrm{g} / \mathrm{kg}$.

\section{Criteria for acceptance/rejection of the lot}

Criteria for accepting/rejecting the lots in Brazil are, by this time, in course to be established by the Ministries of Health 
and of Agriculture and should then be followed. To date, the tolerance level (guideline) issued for aflatoxin in foods for human consumption that is: $20 \mu \mathrm{g} / \mathrm{kg}$ of $B_{1}+B_{2}+G_{1}+G_{2}$, established by the Ministry of Agriculture (6) in 1996, adopting the Mercosul guidelines. However, it should be emphasized that, in practice and for precaution, a lower value should be considered because of the high variability of aflatoxin occurrence in the lots. Accepting a lot of unprocessed grain whose aflatoxin analytical result is under but near $20 \mathrm{~m} \mu / \mathrm{kg}$ may not be safe.

\section{Operating Characteristic Curves (OC curves)}

For calculation of the OC curves (a typical OC curve can be seen in Fig. 3) for in-shell and shelled peanuts and shelled corn, the following critical factors were chosen:

\section{In-shell peanuts: (Fig. 4)}

Guideline: $20 \mu \mathrm{g} / \mathrm{kg}$ (aflatoxins $\mathrm{B}_{1}+\mathrm{B}_{2}+\mathrm{G}_{1}+\mathrm{G}_{2}$ )

Acceptance level $=$ Guideline level (The above level is the recommended Brazilian and Mercosul guideline).

Sample size: $7.0 \mathrm{~kg}$ (pods). The resulting weight after the 7.0 $\mathrm{kg}$ are shelled and that will result in approximately $5.0 \mathrm{~kg}$ of shelled peanuts.

Comminution: Hammer mill (\#14 screen)

Test portion: $100 \mathrm{~g}$

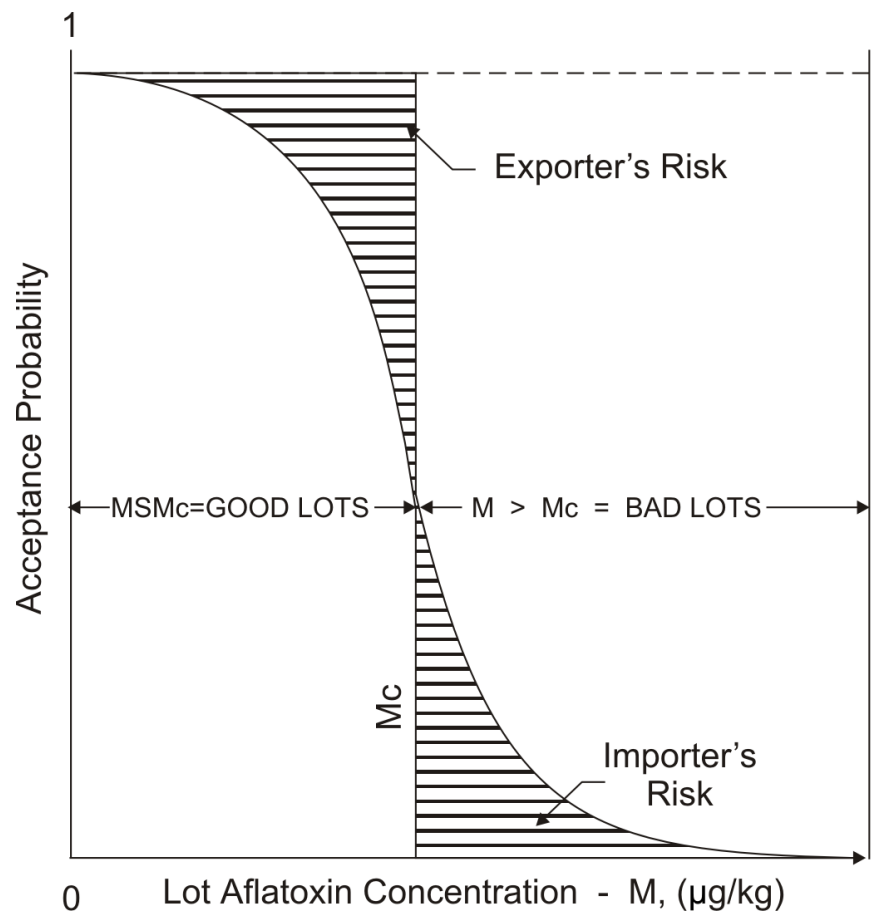

Figure 3. Typical operating characteristic (OC) curve for evaluating sampling plans.
Analytical method: TLC, with a detection limit of, at least, $1 \mu \mathrm{g} / \mathrm{kg}$

\section{Raw shelled peanuts: (Fig. 5)}

Guideline: $20 \mu \mathrm{g} / \mathrm{kg}$ (aflatoxins $\mathrm{B}_{1}+\mathrm{B}_{2}+\mathrm{G}_{1}+\mathrm{G}_{2}$ )

Sample size: $5.0 \mu \mathrm{g} / \mathrm{kg}$

Comminution: Hammer mill (\#14 screen)

Test portion: $100 \mathrm{~g}$

Analytical method: TLC with a detection limit of, at least, $1 \mu \mathrm{g} / \mathrm{kg}$

Shelled corn: (Fig. 6)

Guideline: $20 \mu \mathrm{g} / \mathrm{kg}$ (aflatoxins $\mathrm{B}_{1}+\mathrm{B}_{2}+\mathrm{G}_{1}+\mathrm{G}_{2}$ )

Sample size: $5.0 \mathrm{~kg}$

Comminution: Hammer mill (\#20 screen)

Test portion: $50 \mathrm{~g}$

Analytical method: TLC with a detection limit of, at least, $1 \mu \mathrm{g} / \mathrm{kg}$.

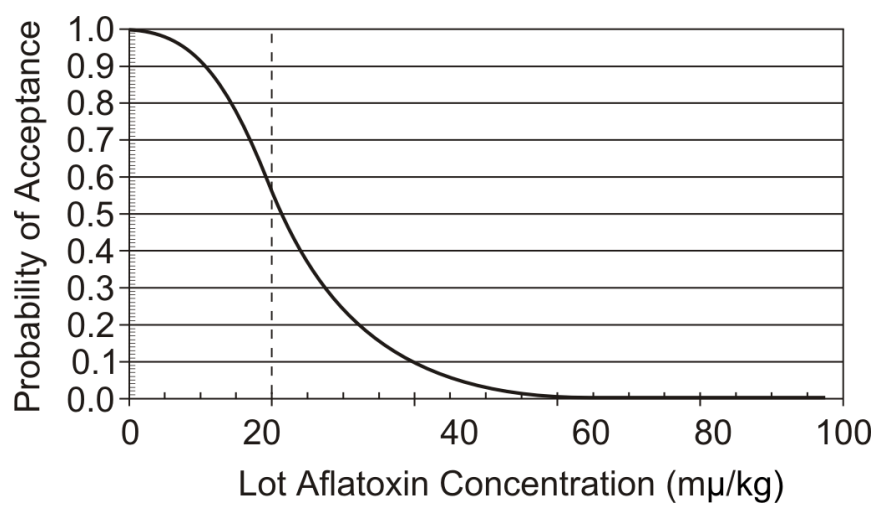

Figure 4. Shelled Corn, 5 kg, Hammer Mill 50 g, 1 TLC, 20 ppb acc/rej Limit.

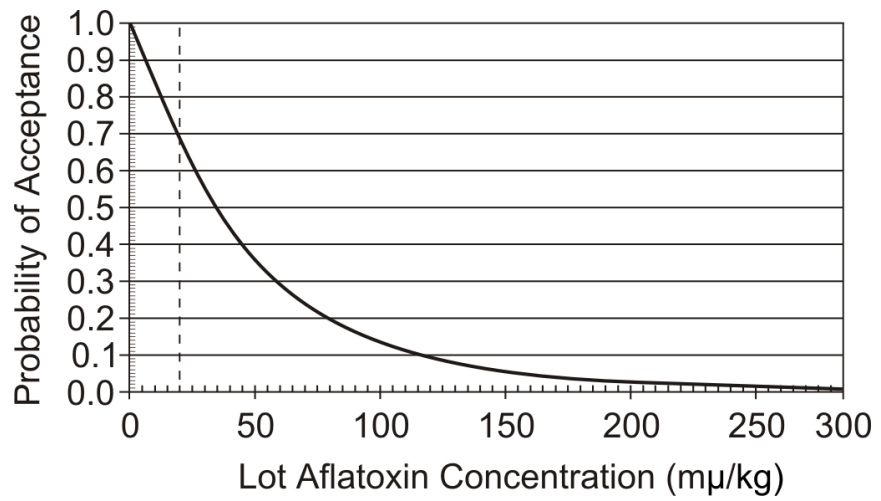

Figure 5. OC Curve for Shelled Peanuts, $5 \mathrm{~kg}$, Hammer Mill $100 \mathrm{~g}$, 1 TLC, 20 ppb acc/rej Limit. 


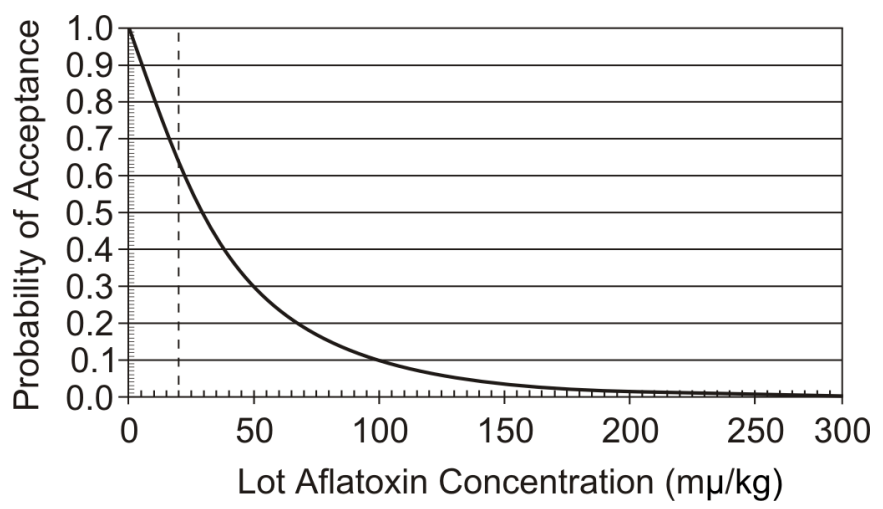

Figure 6. Inshell Peanuts, 7 kg, Hammer Mill 100 g, 1 TLC, 20 ppb acc/rej Limit.

\section{ACKNOLEDGEMENTS}

The author is very grateful to Dr. Thomas B. Whitaker, USDA/ ARS, 124 Weaver Lab, NC State University, Raleigh, NC 276957625 , USA, for his critical review of this document, for the development of the OC Curves for in-shell and shelled peanuts and shelled corn, and for the summary data concerning the performance of a sampling plan applied to shelled peanuts with the same critical factors as this method. The author is also very grateful to Prof. Ray Coker, of the Food Safety Food Management and Marketing Group, Natural Resources Institute, University of Greenwich, Central Avenue, Chatham Maritime, Chatham, Kent, ME4 4TB, UK, also for his critical review of this document and for the valuable suggestions.

\section{RESUMO}

\section{Sistema de amostragem para análise de aflatoxinas em amendoim e milho: uma atualização}

O objetivo deste trabalho foi atualizar a metodologia de amostragem para análise de micotoxinas em grãos, anteriormente publicada pelo autor. As alterações propostas tiveram por base a experiência adquirida na sua utilização e em recomendações da FAO. Esta atualização restringe a aplicação do método anterior e estabelece um plano de amostragem para análise de aflatoxina em amendoim e em milho por meio de fórmulas modificadas, o mínimo de sacos ou pontos (quando a granel) dos quais devem ser retiradas amostras incrementais para constituir uma amostra. Expoentes fracionários (raiz quadrada) das fórmulas diminuem proporcionalmente o número de sacos/ pontos a serem amostrados, à medida que o lote aumenta de tamanho. Curvas de operação característica (OC) desenvolvidas para amendoim em casca e descascado e milho, bem como curvas de tendência dos coeficientes de variação, para diferentes tamanhos de amostra (peso), são apresentadas.

Palavras-chave: Amostragem, amendoim, milho, aflatoxina, análise.

\section{REFERENCES}

1. Cucullu, A.F.; Lee, I.S.; Mayne, R.Y.; Goldblatt, L.A. Determination of aflatoxins in individual peanuts and peanut sections. J. Am. Oil Chem. Soc., 43: 89-92, 1966

2. FAO. Sampling Plans for Aflatoxin Analysis in Peanuts and Corn. FAO Food and Nutrition Paper No. 55, 1993.

3. Fonseca, H. Sistema de amostragem para análise de aflatoxina em grãos. Rev. Microbiol., 21(2): 66-70, 1991

4. Jewers, K. Mycotoxins in food - the application of survey and quality control. Royal Soc. Health J., 102: 114-118, 1982.

5. Koltun, S.P.; Gardner, H.K., Jr.; Dollear, F.G.; Rayner, E.T. Physical properties and aflatoxin content of individual cateye fluorescent cottonseeds. J. Am. Oil Chem. Soc., 51: 178-180, 1974.

6. Brasil. Ministério da Agricultura. Portaria no.183 de 21 de março de 1996. Diário Oficial da União de 25 de março de 1996, Seção I, p.4929.

7. Brasil. Ministério da Saúde. Comissão Nacional de Normas e Padrões para Alimentos. Resolução no 34/76, Diário Oficial da União, 19 de janeiro de 1977.

8. Robertson, J.A.; Lee, L.S.; Cucullu, A.F.; Goldblatt, L.A. Assay of aflatoxin in peanuts and peanut products using acetone-hexanewater for extraction. J. Am. Oil Chem. Soc., 42: 467-471, 1965.

9. Shotwell, O.L.; Goulden, M.L.; Hesseltine, C.W. Aflatoxin distribution in contaminated corn. Cereal Chem., 51: 492-499, 1974.

10 Whitaker, T.; Wiser, E. Theoretical investigations into the accuracy of sampling shelled peanuts for aflatoxin. J. Am. Oil Chem. Soc., 46: 377-379, 1969.

11. Whitaker, T.; Dickens, J.W.; Wiser, E. Design and analysis of sampling plans to estimate aflatoxin concentrations in shelled peanuts. J. Am Oil Chem. Soc., 47: 501-504, 1970.

12. Whitaker, T.; Dickens, J.W.; Monroe R. Comparison of the observed distribution of aflatoxin in shelled peanuts to the negative binomial distribution. J. Am. Oil Chem. Soc., 49: 590-593, 1972.

13. Whitaker, T.; Dickens, J.W.; Monroe, R. Variability of aflatoxin test results. J. Am. Oil Chem. Soc., 51: 214-218, 1974a.

14. Whitaker, T.; Dickens, J.W.; Wiser, E.; Monroe R. Development of the method to evaluate sampling plans used to estimate aflatoxin concentration in lots of shelled peanuts. IUPAC Technical Reports, No. 10, 1974b.

15. Whitaker, T. Sampling granular foodstuffs for aflatoxin. Pure App Chem., 49: 1709-1717, 1977. 


\section{ANNEX 1}

\begin{tabular}{|c|c|c|c|}
\hline \multicolumn{4}{|c|}{ Table for sampling in-shell peanuts in sacks } \\
\hline Prof: Homero & Fonseca & $N S=6 \sqrt{S L}$ & \\
\hline $\begin{array}{c}\mathrm{SL}=\text { No. of } \\
\text { sacks } \\
\text { in lot }\end{array}$ & $\begin{array}{c}\mathrm{NS}=\text { No. of } \\
\text { sacks to be } \\
\text { sampled }\end{array}$ & $\begin{array}{c}\mathrm{SW}=\text { Sample } \\
\text { weight } \\
\mathrm{NS} \times 0.2 \mathrm{~kg}\end{array}$ & $\begin{array}{c}\text { No. of samples } \\
\text { to analyze } \\
\mathrm{SW} / 7 \mathrm{~kg}\end{array}$ \\
\hline 10 & 19.0 & 3.8 & 1 \\
\hline 20 & 26.8 & 5.4 & 1 \\
\hline 30 & 32.9 & 6.6 & 1 \\
\hline 40 & 37.9 & 7.6 & 1 \\
\hline 50 & 42.4 & 8.5 & 1 \\
\hline 60 & 46.5 & 9.3 & 1 \\
\hline 70 & 50.2 & 10.0 & 1 \\
\hline 80 & 53.7 & 10.7 & 2 \\
\hline 90 & 56.9 & 11.4 & 2 \\
\hline 100 & 60.0 & 12.0 & 2 \\
\hline 200 & 84.9 & 17.0 & 2 \\
\hline 300 & 103.9 & 20.8 & 3 \\
\hline 400 & 120.0 & 24.0 & 3 \\
\hline 500 & 134.0 & 26.8 & 4 \\
\hline 600 & 147.0 & 29.4 & 4 \\
\hline 700 & 158.7 & 31.7 & 5 \\
\hline 800 & 169.7 & 33.9 & 5 \\
\hline 900 & 180.0 & 36.0 & 5 \\
\hline 1000 & 189.7 & 37.9 & 5 \\
\hline 1100 & 199.0 & 39.8 & 6 \\
\hline 1200 & 207.8 & 41.6 & 6 \\
\hline 1300 & 216.3 & 43.3 & 6 \\
\hline 1400 & 224.5 & 44.9 & 6 \\
\hline 1500 & 232.4 & 46.5 & 7 \\
\hline 1600 & 240.0 & 48.0 & 7 \\
\hline 1700 & 247.4 & 49.5 & 7 \\
\hline 1800 & 254.6 & 50.9 & 7 \\
\hline 1900 & 261.5 & 52.3 & 7 \\
\hline 2000 & 268.3 & 53.7 & 8 \\
\hline
\end{tabular}

ANNEX 2

\begin{tabular}{|c|c|c|c|}
\hline \multicolumn{4}{|c|}{ Table for sampling shelled peanuts in sacks } \\
\hline Prof. Homer & Fonseca & $N S=4 \sqrt{S L}$ & \\
\hline $\begin{array}{c}\text { No. of } \\
\text { sacks } \\
\text { in lot }=\mathrm{SL}\end{array}$ & $\begin{array}{l}\mathrm{NS}=\text { No. of } \\
\text { sacks to be } \\
\text { sampled }\end{array}$ & $\begin{array}{c}\mathrm{SW}=\text { Sample } \\
\text { weight } \\
\mathrm{NS} \times 0.2 \mathrm{~kg}\end{array}$ & $\begin{array}{c}\text { No. of samples } \\
\text { to analyze } \\
\mathrm{SW} / 5 \mathrm{~kg}\end{array}$ \\
\hline 10 & 12.6 & 2.5 & 1 \\
\hline 20 & 17.9 & 3.6 & 1 \\
\hline 30 & 16.4 & 3.3 & 1 \\
\hline 40 & 25.3 & 5.1 & 1 \\
\hline 50 & 28.3 & 5.7 & 1 \\
\hline 60 & 31.0 & 6.2 & 1 \\
\hline 70 & 33.5 & 6.7 & 1 \\
\hline 80 & 35.8 & 7.2 & 1 \\
\hline 90 & 37.9 & 7.6 & 2 \\
\hline 100 & 40.0 & 8.0 & 2 \\
\hline 200 & 56.6 & 11.3 & 2 \\
\hline 300 & 69.3 & 13.9 & 3 \\
\hline 400 & 80.0 & 16.0 & 3 \\
\hline 500 & 89.4 & 17.9 & 4 \\
\hline 600 & 98.0 & 19.6 & 4 \\
\hline 700 & 105.8 & 21.2 & 4 \\
\hline 800 & 113.1 & 22.6 & 5 \\
\hline 900 & 120.0 & 24.0 & 5 \\
\hline 1000 & 126.5 & 25.3 & 5 \\
\hline 1100 & 132.7 & 26.5 & 5 \\
\hline 1200 & 138.6 & 27.7 & 6 \\
\hline 1300 & 144.2 & 28.8 & 6 \\
\hline 1400 & 149.7 & 29.9 & 6 \\
\hline 1500 & 154.9 & 31.0 & 6 \\
\hline 1600 & 160.0 & 32.0 & 6 \\
\hline 1700 & 164.9 & 33.0 & 7 \\
\hline 1800 & 169.7 & 33.9 & 7 \\
\hline 1900 & 174.4 & 34.9 & 7 \\
\hline 2000 & 178.9 & 35.8 & 7 \\
\hline
\end{tabular}


ANNEX 3

\begin{tabular}{|c|c|c|c|}
\hline \multicolumn{4}{|c|}{ Table for sampling in-shell peanuts in bulk } \\
\hline Prof. Homero & Fonseca & $N P=24 \sqrt{T L}$ & \\
\hline $\begin{array}{c}\mathrm{TL}=\text { No. of } \\
\text { tons } \\
\text { in lot }\end{array}$ & $\begin{array}{l}\text { NP - No. of } \\
\text { points to be } \\
\text { sampled }\end{array}$ & $\begin{array}{c}\mathrm{SW}=\text { Sample } \\
\text { weight } \\
\mathrm{NS} \times 0.2 \mathrm{~kg}\end{array}$ & $\begin{array}{l}\text { No. of samples } \\
\text { to analyze } \\
\mathrm{SW} / 7 \mathrm{~kg}\end{array}$ \\
\hline 5 & 53.7 & 10.7 & 1 \\
\hline 10 & 75.9 & 15.2 & 1 \\
\hline 20 & 107.3 & 21.5 & 1 \\
\hline 30 & 131.5 & 26.3 & 4 \\
\hline 40 & 151.8 & 30.4 & 4 \\
\hline 50 & 169.7 & 33.9 & 5 \\
\hline 60 & 185.9 & 37.2 & 5 \\
\hline 70 & 200.8 & 40.2 & 6 \\
\hline 80 & 214.7 & 42.9 & 6 \\
\hline 90 & 227.7 & 45.5 & 7 \\
\hline 100 & 240.0 & 48.0 & 7 \\
\hline 150 & 293.9 & 58.8 & 8 \\
\hline 200 & 339.4 & 67.9 & 10 \\
\hline 250 & 379.5 & 75.9 & 11 \\
\hline 300 & 415.7 & 83.1 & 12 \\
\hline 350 & 449.0 & 89.8 & 13 \\
\hline 400 & 480.0 & 96.0 & 14 \\
\hline 450 & 509.1 & 101.8 & 15 \\
\hline 500 & 536.7 & 107.3 & 15 \\
\hline
\end{tabular}

\section{ANNEX 4}

\begin{tabular}{|c|c|c|c|}
\hline \multicolumn{4}{|c|}{ Table for sampling shelled corn in bulk } \\
\hline Prof: Homero & Fonseca & $N P=18 \sqrt{T L}$ & \\
\hline $\begin{array}{c}\mathrm{TL}=\text { No. of } \\
\text { tons } \\
\text { in lot }\end{array}$ & $\begin{array}{l}\text { NP - No. of } \\
\text { points to be } \\
\text { sampled }\end{array}$ & $\begin{array}{c}\mathrm{SW}=\text { Sample } \\
\text { weight } \\
\mathrm{NS} \times 0.2 \mathrm{~kg} \\
\end{array}$ & $\begin{array}{c}\text { No. of samples } \\
\text { to analyze } \\
\text { SW/5 kg }\end{array}$ \\
\hline 5 & 40.2 & 8.0 & 2 \\
\hline 10 & 56.9 & 11.4 & 2 \\
\hline 15 & 69.7 & 13.9 & 3 \\
\hline 20 & 80.5 & 16.1 & 3 \\
\hline 25 & 90.0 & 18.0 & 4 \\
\hline 30 & 98.6 & 19.7 & 4 \\
\hline 35 & 106.5 & 21.3 & 4 \\
\hline 40 & 113.8 & 22.8 & 5 \\
\hline 50 & 127.3 & 25.5 & 5 \\
\hline 60 & 139.4 & 27.9 & 6 \\
\hline 70 & 150.6 & 30.1 & 6 \\
\hline 80 & 161.0 & 32.2 & 6 \\
\hline 90 & 170.8 & 34.2 & 7 \\
\hline 100 & 180.0 & 36.0 & 7 \\
\hline 150 & 220.5 & 44.1 & 9 \\
\hline 200 & 254.6 & 50.9 & 10 \\
\hline 250 & 284.6 & 56.9 & 11 \\
\hline 300 & 311.8 & 62.4 & 12 \\
\hline 350 & 336.7 & 67.3 & 13 \\
\hline 400 & 360.0 & 72.0 & 14 \\
\hline 450 & 381.8 & 76.4 & 15 \\
\hline 500 & 402.5 & 80.5 & 16 \\
\hline 600 & 440.9 & 88.2 & 18 \\
\hline 700 & 476.2 & 95.2 & 19 \\
\hline 800 & 509.1 & 101.8 & 20 \\
\hline 900 & 540.0 & 108.0 & 22 \\
\hline 1000 & 569.2 & 113.8 & 23 \\
\hline 2000 & 805.0 & 161.0 & 32 \\
\hline
\end{tabular}

